\title{
Attraction of Anopheles gambiae to odour baits augmented with heat and moisture
}

\author{
Evelyn A Olanga ${ }^{1,2}$, Michael N Okal ${ }^{1}$, Phoebe A Mbadi ${ }^{1}$, Elizabeth D Kokwaro ${ }^{2}$, Wolfgang R Mukabana ${ }^{1,3^{*}}$
}

\begin{abstract}
Background: The search for a standard human surrogate in the form of a synthetic mosquito attractant has been the goal of many laboratories around the world. Besides alleviating the occupational risk subjected to volunteers participating in vector surveillance and control, discovery of potent attractants underpins the development and deployment of mass trapping devices for controlling mosquito-borne diseases.

Methods: A dual-port olfactometer was used to assess behavioural responses of female Anopheles gambiae mosquitoes towards synthetic versus natural (whole human emanations and worn socks) attractants. The synthetic attractants included a standard blend consisting of ammonia, carbon dioxide and water; and Ifakara blend 1 (IB1) consisting of various aliphatic carboxylic acids. Natural attractants were obtained from two males known to be less and highly attractive (LA and HA, respectively) to the mosquitoes. Mosquito responses to the volunteers' worn socks were also investigated. The effect of heat $\left(25-27^{\circ} \mathrm{C}\right)$ and moisture $(75-85 \%)$ on the mosquito behavioural responses was determined.
\end{abstract}

Results: A significantly higher proportion of mosquitoes was attracted to each volunteer when compared to the standard blend. Whereas the proportion of mosquitoes attracted to person LA versus IB1 (49\% versus 51\%, respectively; $\mathrm{P}=0.417$ ) or his worn socks did not differ ( $61 \%$ versus $39 \%$, respectively; $\mathrm{P}=0.163$ ), far more mosquitoes were attracted to person HA relative to IB1 (96\% versus 4\%; $P=0.001$ ) or his worn socks (91\% versus 9\%; $\mathrm{P}=0.001$ ). Person HA attracted a significantly higher proportion of mosquitoes than his worn socks, the standard blend and IB1 when these were augmented with heat, moisture or both $(P=0.001)$. Similar results were obtained with person LA except that the proportion of mosquitoes attracted to him versus his worn sock augmented with heat $(P=0.65)$ or IB1 augmented with heat and moisture $(P=0.416)$ did not differ significantly.

Conclusions: These findings indicate that olfactory cues are key mediators of the mosquito host-seeking process and that heat and moisture play a minor role. The need for a standard, highly stringent positive control for screening synthetic attractants is strongly highlighted.

\section{Background}

Anopheles gambiae sensu stricto, i.e. the principal vector of malaria in sub-Saharan Africa [1-4], locates its blood meal hosts largely based on olfactory cues [5]. Physical cues, encompassing heat and moisture, also play a role that is hitherto not well understood [6]. Dissecting and analysing the broad spectrum of human emanations [7] can provide an important basis for developing synthetic compounds or blends with desirable attractant [8], repellent or attractant "masking" properties [9]. Certainly, several compounds identified from human emanations have

\footnotetext{
* Correspondence: rmukabana@yahoo.co.uk

${ }^{1}$ International Centre of Insect Physiology and Ecology, PO Box 30772 00100, GPO, Nairobi, Kenya
}

been demonstrated to exhibit attractant properties under varying experimental conditions [10-15].

Although the objectives of developing potent insect attractants are diverse, the central goal lies in pest and vector control $[8,16]$. With respect to mosquitoes, impact on target populations can be achieved by mass trapping $[17,18]$ or lure and kill technology [19]. Despite the underlying conceptual, technical, logistical and financial limitations, mass trapping has been most explored for mosquito population reduction [16]. These strategies are, regardless of few field successes $[17,18]$, still being developed. Current efforts centre on searching for new attractants and attractant formulations [14,15,20,21], improving on existing ones [13], and developing trapping

\section{Biomed Central}


devices [22,23]. Efficacy trials under field [14] and semifield conditions are also underway [15,24].

The potency of an attractant is determined by comparing the relative attraction of target insects to it, versus its natural source or calculating the percentage of catch from a known insect population $[16,25]$. Thus, candidate synthetic attractants of anthropophilic mosquitoes have been evaluated by comparing their attractiveness to hostseeking mosquitoes against odour from human feet [24-27] and hands [28-30]. No attempts have been made to evaluate the efficacy of candidate attractants based on the full spectrum of human body emanations, yet this is what determines the end point of the entire host-seeking process [31]. Identifying a synthetic blend that attracts mosquitoes much the same as a human being [32] can enhance its usefulness in developing powerful tools for vector surveillance [5] and control $[8,16,19]$.

In this study, the behavioural responses of An. gambiae towards two candidate synthetic attractant blends were evaluated. The key objectives were to (i) determine the relative response of An. gambiae towards the attractants in comparison to human volunteers, and (ii) investigate the effect of heat and moisture on mosquito responses to the synthetic attractants. Attraction of mosquitoes to the blends used in this study had been determined previously [15].

\section{Methods}

\section{Mosquitoes}

Experiments were conducted using the Mbita strain of Anopheles gambiae sensu stricto (hereafter referred to as An. gambiae). The mosquitoes were reared under ambient climatic conditions at insectaries of the International Centre of Insect Physiology and Ecology (ICIPE) located at Mbita Point, western Kenya. Mosquito eggs were dispensed into plastic trays containing filtered water from Lake Victoria. Hatched larvae were fed on Tetramin ${ }^{\circ}$ baby fish food three times per day. Pupae were harvested daily and transferred into clean cups half-filled with filtered lake water. Cups containing pupae were placed in mesh-covered cages $(30 \times 30 \times 30 \mathrm{~cm})$ prior to adult emergence. Emerged adult mosquitoes were fed on $6 \%$ glucose solution through wicks made from adsorbent tissue paper. All experiments utilized 100 adult female mosquitoes aged 3-6 days old. The mosquitoes were starved for 8 hours and did not receive a blood meal before experiments were commenced. Starving mosquitoes were provided with water on cotton towels placed on top of mosquito holding cups.

\section{Behavioural stimuli}

Two male volunteers, aged 32 and 33 years old, acted as natural sources of host-seeking cues. One of the volunteers was less attractive (LA) and the other highly attractive (HA) to host-seeking, female An. gambiae mosquitoes [33]. The volunteers' wore cotton socks for 8 hours to collect their foot odours. This acted as an alternative natural source of host-seeking cues. The volunteers bathed with non-perfumed soap half an hour before onset of experiments. They wore short trousers only during the experimental periods. Their malaria parasite infection status was determined daily through microscopic examination of giemsa stained blood smears.

Synthetic stimuli were derived from two odour blends i.e. a standard blend [consisting of $\mathrm{CO}_{2}(500 \mathrm{ml} / \mathrm{min})$, ammonia (2.5\%) and distilled $\mathrm{H}_{2} \mathrm{O}$ ] and Ifakara blend 1 (IB1) [consisting of propionic acid (0.1\%), butanoic acid (1\%), pentanoic acid $(0.01 \%), 3-$ methyl butanoic acid $(0.001 \%)$, heptanoic acid $(0.01 \%)$, octanoic acid $(0.01 \%)$, tetradecanoic acid $(0.01 \%)$, ammonia $(2.5 \%)$, lactic acid (85\%), distilled water and carbon dioxide $(500 \mathrm{ml} / \mathrm{min})]$. Strips of nylon sock material (90\% polyamide and $10 \%$ spandex) measuring $26 \mathrm{~cm}$ long by $1 \mathrm{~cm}$ wide were dipped in separate one millilitre volumes of chemical constituents characteristic of a specific blend. Individual strips were not dipped in more than one chemical. Soaked strips were air dried at room temperature for five hours prior to experiments [15]. To constitute a blend a number of dried strips, selected based on the components of the standard blend or blend IB1, were tied together on one end prior to use as bait in experiments. The carbon dioxide component of the blends was supplied through gas tubing. All chemicals, except $\mathrm{CO}_{2}$, were purchased from Sigma-Aldrich Chemie $\mathrm{GmbH}$ (Germany). Carbon dioxide (industrial grade) was purchased from Carbacid Investments Ltd, Kenya.

\section{Experimental setup}

All experiments were carried out using a model of a previously described olfactometer [33] modified to accommodate two, instead of three human subjects as sources of host-seeking stimuli (Figure 1).

\section{Testing functional integrity of the dual-choice setup}

The functional integrity of the experimental setup was assessed through three fundamental binary assays: an empty tent versus an empty tent, the standard blend versus the standard blend and person LA versus person HA. Each experimental comparison was carried out for four nights with rotation of stimuli between the tents to avoid positional bias. Two experiments were conducted per night; between 1930 to 2000 hours and 2030 to 2100 hours. Temperature and relative humidity of tents occupied by person LA and person HA were recorded in all replicates using data loggers (Tinytag ${ }^{\circ}$ ). The average temperature and relative humidity readings in tents occupied by each individual were calculated.

\section{Responses to synthetic attractants}

Comparative mosquito behavioural responses to human emanations and synthetic attractants were evaluated. 


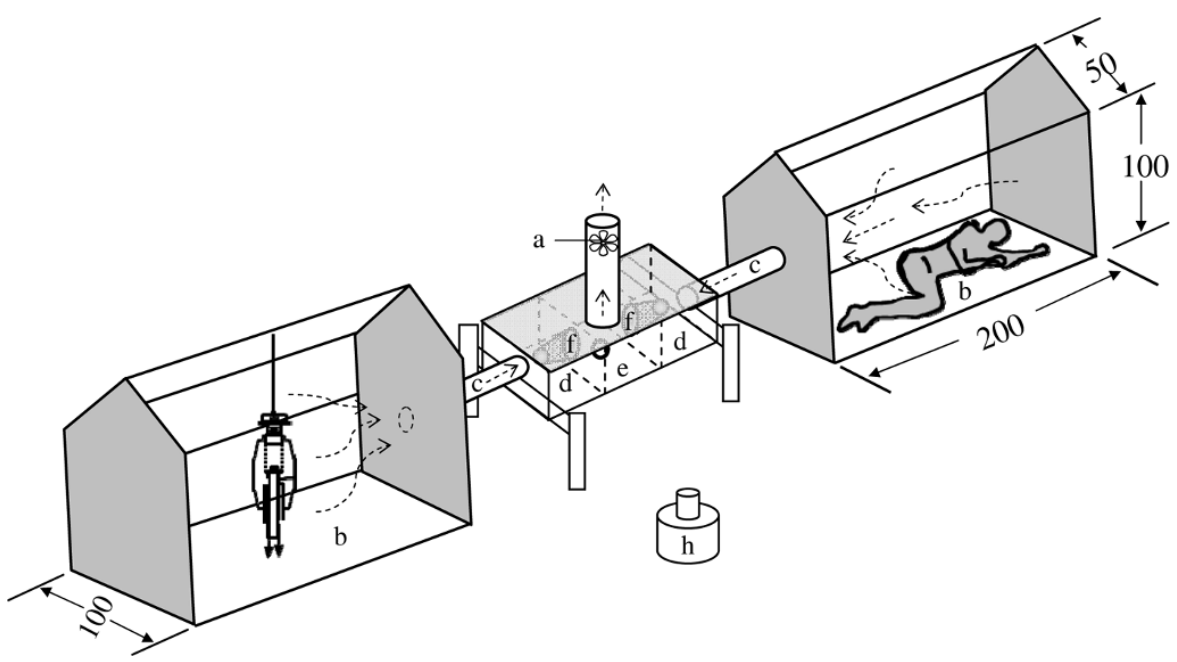

Figure 1 The dual-choice experimental setup. The fan (a) drew air ( 130 L/min/tent) from the two tents (b) to the outside environment via PVC pipes (c), trap chambers (d) and central choice chamber (e). An exit trap (f) opened into each trap chamber. The fan pipe and the release cup (h) were fitted on top and on the bottom of the choice chamber, respectively, through circular holes. The trap and choice chamber measured $30 \times 15 \times 20$ and $30 \times 20 \times 20$, respectively. Diagrams are not drawn to scale; all dimensions are in centimeters.

The specific binary tests included (i) person LA versus an empty tent, (ii) person LA versus the standard blend, (iii) person LA versus blend IB1, (iv) person LA versus his worn sock, (v) person HA versus an empty tent, (vi) person HA versus the standard blend, (vii) person HA versus blend IB1 and (viii) person HA versus his worn sock. The competing odour sources were placed in separate tents (Figure 1). Each experimental comparison was carried out for four nights. Two experiments were conducted per night; between 1930 to 2000 hours and 2030 to 2100 hours. Odour sources were alternated between tents on each experimental night. Mosquitoes orienting towards odour laden air emanating from a specific tent were recovered from collecting cages present in trap chambers adjacent to that tent, counted and recorded as having been attracted by the material baiting the tent. Natural host odours were obtained from volunteers either by sucking air from tents in which they lay or by using $100 \%$ cotton socks worn by them over a period of 8 hours and placed in an MM-X trap. Natural odour collected onto participants' worn socks and synthetic odour in the form of the standard blend or IB1 were dispensed using MM-X traps (American Biophysics Corporation, North Kingstown, RI, USA). To do this, the worn socks or bundles of nylon strips representative of the standard blend or IB1 were placed inside the central tube of an MM-X trap before power (12 V) was applied.

Natural human odours (whole human emanations and foot odours) served as positive controls against which candidate synthetic attractants (standard blend and Ifakara blend 1) were screened.

\section{Responses to synthetic attractants augmented with heat} and moisture

Temperature and/or relative humidity of tents containing the candidate synthetic attractants were raised to the levels pre-determined for tents occupied by person LA or person HA, respectively, depending on whether person LA or person HA participated as the human odour source. The aim was to determine the effect of heat and/or moisture on attraction of mosquitoes to attractants of synthetic (i.e. the standard blend and blend IB1) and natural (worn socks) origin. Thus, the effect of heat on relative attractiveness of person LA was determined by comparing the number of mosquitoes attracted to person LA versus those attracted to the competitor stimuli (worn socks, standard blend or blend IB1) when heated to the average temperature predetermined for a tent occupied by person LA. The effect of heat on relative attractiveness of person HA was determined similarly. Likewise, the effect of moisture on relative attractiveness of person LA or person HA was determined by comparing the number of mosquitoes attracted to person LA or person HA versus those attracted to the competitor stimuli (worn socks, standard blend or blend IB1) when moisturized to the average relative humidity predetermined for a tent occupied by person LA or person HA. Equally, the combined effect of heat and moisture on relative attractiveness of person LA or person HA was determined by comparing the number of mosquitoes attracted to person LA or person HA versus those attracted to the competitor stimuli (worn socks, standard blend or blend IB1) when 
heated and moistened to the average temperature and relative humidity predetermined for tents occupied by person LA or person HA. The tents were heated and/or humidified using a portable heater (Conrad Electronics ${ }^{\circ}$ ) regulated with a thermostat and/or a portable humidifier regulated with an inbuilt humidistat (Honeywell ${ }^{\circ}$ ).

\section{Ethical considerations}

The goal, objectives, rationale and procedures of the study were explicitly explained to the human subjects until they understood them clearly. The volunteers' consent to participate in the study was sought thereafter and recruitment in the study done upon consent. This study was approved by the joint Kenyatta National Hospital/ University of Nairobi ethical review committee (protocol approval number P102/7/2004 amended in 2008).

\section{Statistical analysis}

The factors that would potentially affect the mosquito responses i.e. tent and experimental period were both categorical, while behavioural responses of individual mosquitoes were mutually exclusive. Conformity of the datasets to a Poisson distribution was authenticated through dispersion tests, which examined whether means equalled the variances [34]. Rigorous statistical analyses were undertaken thereafter. Using Generalized Linear Models [35] the number of mosquitoes attracted to the different sources of behavioural stimuli (human subjects, their worn socks or synthetic attractants) was modelled as a proportion of the total number of mosquitoes recovered from the choice chamber, the release cup and the two trap chambers. The data were transformed to assume a normal distribution using a logarithm link function. The analyses allowed for differences to be determined between odour baits, traps and test periods. A model of the form $\log \left(\mu_{i j k}\right)=\mathrm{E}_{i}+\mathrm{T}_{j}+\mathrm{B}_{k}$, where $\mathrm{E}_{i}, \mathrm{~T}_{j}$ and $\mathrm{B}_{k}$ are the parameter estimates for experimental period $i$, trap $j$ and behavioural stimulus $k$, respectively, was fitted. Thus, the proportion of mosquitoes attracted to behavioural stimulus $\mathrm{B}_{k}$ was estimated by the following equation:

$$
\mathrm{B}_{i j k}=\frac{\mathrm{E}_{i}+\mathrm{T}_{j}+\mathrm{B}_{k}}{\exp \left(\mathrm{E}_{i}+\mathrm{T}_{j}+\mathrm{B}_{k}\right)}
$$

The extent to which different pairs of contrasting behavioral stimuli activated or attracted mosquitoes allowed for differences between test periods only. Parameter estimates provided an index of attraction of mosquitoes to the different behavioural stimuli. The symmetry and functional integrity of the experimental setup was assessed using tent $\mathrm{A}$, tent $\mathrm{A}$ and person $\mathrm{HA}$ as references in three baseline binary assays i.e. empty tent versus empty tent, standard blend versus standard blend and person HA versus person LA, respectively. In all other binary assays (i.e. those assessing relative attraction of humans to synthetic attractants on their own or when augmented with heat, moisture or both) the human subjects posed as baseline references against which the degree of attraction of the mosquitoes to the synthetic attractants was compared. The General statistical software programme (GenStat Discovery Edition 3) was used to analyse the data [36].

\section{Results}

A total of 30 dual-choice tests were conducted over a period of 120 nights. The experiments were carried out between February and November, 2008. A total of 24,000 laboratory reared female An. gambiae mosquitoes were used. Mosquito behavioural responses to competing stimuli were assessed within the short-range phase ( $<2$ metres) of attraction. Two human subjects, neither of whom was found with malaria parasites throughout the study, participated in the experiments.

\section{Testing functional integrity of the dual-choice setup}

No mosquitoes were caught in the trapping chambers when both tents were left empty. Subsequent tests found no significant differences in the number of mosquitoes attracted to the standard blend when competed against itself $(\mathrm{P}=0.889)$. The relative attractiveness of the volunteers differed significantly $(\mathrm{P}<0.001)$. One hundred percent of the mosquitoes were attracted to the person HA. The average temperature and relative humidity in the tents occupied by the less and highly attractive individuals were $24.98^{\circ} \mathrm{C}$ and $75.28 \%$ and $25.5^{\circ}$ $\mathrm{C}$ and $80.43 \%$, respectively. These three experiments confirmed that the experimental setup was well suited for discriminating mosquito behavioural responses to candidate behavioural stimuli (Table 1).

\section{Responses to synthetic attractants}

A higher proportion of mosquitoes were attracted to the less as well as the highly attractive person used in the study when compared to the standard blend (63\% versus $37 \%, \mathrm{P}<0.001$ and $80 \%$ versus $19 \%, \mathrm{P}<0.001$, respectively). On the contrary, whereas the proportion of mosquitoes attracted to the less attractive person versus blend IB1 ( $49 \%$ versus $51 \%$, respectively; $\mathrm{P}=0.417$ ) or his worn socks did not differ (61\% versus $39 \%$, respectively; $\mathrm{P}=0.613$ ), far more mosquitoes were attracted to the highly attractive individual in comparison to blend IB1 (96\% versus $4 \%$; $P=0.001)$ or his worn socks $(91 \%$ versus $9 \% ; \mathrm{P}=0.001)$. The less as well as the highly attractive individual attracted a significantly higher proportion of mosquitoes compared to empty tents $(83 \%$ versus $17 \%, \mathrm{P}<0.001$ and $93 \%$ versus $7 \%, \mathrm{P}<0.001$, respectively). These results are depicted in Table 2 .

Responses to synthetic attractants augmented with heat and moisture

There was no significant difference $(P=0.650)$ in the proportion of mosquitoes attracted to person LA (52\%) when compared to his worn socks (48\%) augmented with 
Table 1 Proportions of mosquitoes attracted (reference) in the absence of human emanations or in the presence of synthetic and natural (human-derived) behavioural stimuli in binary assays

\begin{tabular}{|c|c|c|c|c|c|c|}
\hline \multicolumn{2}{|c|}{ Behavioural stimuli } & \multirow[t]{2}{*}{$\mathbf{N}$} & \multirow[t]{2}{*}{$\mathbf{P}$} & \multirow[t]{2}{*}{ Reference } & \multicolumn{2}{|c|}{ Mosquito behavioral responses } \\
\hline Reference & Other & & & & $\mathbf{n}$ & Net attraction \\
\hline Tent A (empty) & Tent B (empty) & 8 & 1.000 & 0.00 & 559 & $0.00^{\mathrm{a}}$ \\
\hline Standard Blend & Standard Blend & 8 & 0.889 & 0.51 & 527 & $0.10^{b}$ \\
\hline Person HA & Person LA & 8 & 0.001 & 1.00 & 541 & $0.13^{b}$ \\
\hline
\end{tabular}

$\mathrm{N}$ refers to the number of replicates. $\mathrm{P}$ values $(\mathrm{P})$ indicate the level of statistical difference between pairs of contrasting stimuli i.e. reference versus other. Proportions of mosquitoes attracted to different reference stimuli (reference) relative to contrasting ones (other) are shown. The total number of mosquitoes collected in the choice and trap chambers $(n)$ and the proportion of these that were attracted to either behavioural stimulus (Net attraction) are shown. Values followed by different letter superscripts in the same column differ significantly.

Table 2 Attraction of Anopheles gambiae to humans versus odours of synthetic and natural origin.

\begin{tabular}{|c|c|c|c|c|c|c|}
\hline \multicolumn{2}{|c|}{ Behavioural stimuli } & \multirow[t]{2}{*}{$\mathbf{N}$} & \multirow[t]{2}{*}{$\mathbf{P}$} & \multirow[t]{2}{*}{ Person } & \multicolumn{2}{|c|}{ Mosquito Behavioural Responses } \\
\hline Person & Other & & & & $\mathbf{n}$ & Net attraction \\
\hline LA & Empty tent & 8 & 0.001 & $83 \%$ & 511 & $0.07^{\mathrm{a}}$ \\
\hline LA & Standard Blend & 8 & 0.001 & $63 \%$ & 538 & $0.04^{b}$ \\
\hline LA & Blend IB1 & 8 & 0.417 & $49 \%$ & 548 & $0.14^{c}$ \\
\hline LA & Worn sock & 8 & 0.613 & $61 \%$ & 629 & $0.16^{\mathrm{c}}$ \\
\hline$H A$ & Empty tent & 8 & 0.001 & $93 \%$ & 563 & $0.28^{d}$ \\
\hline$H A$ & Standard Blend & 8 & 0.001 & $80 \%$ & 444 & $0.27^{d}$ \\
\hline $\mathrm{HA}$ & Blend IB1 & 8 & 0.001 & $96 \%$ & 562 & $0.28^{d}$ \\
\hline $\mathrm{HA}$ & Worn sock & 8 & 0.001 & $91 \%$ & 559 & $0.36^{\mathrm{e}}$ \\
\hline
\end{tabular}

$\mathrm{N}$ refers to the number of replicates. $\mathrm{P}$ values $(\mathrm{P})$ indicate the level of statistical difference between pairs of contrasting stimuli i.e. person versus competing behavioural stimuli (other). Percentages of mosquitoes attracted to the persons are shown. The total number of mosquitoes collected in the choice and trap chambers $(n)$ and the proportion of these that were attracted to either behavioural stimulus (Net attraction) are shown. Values followed by different letter superscripts in the same column differ significantly.

Table 3 Attraction of Anopheles gambiae to humans versus odours of synthetic and natural origin augmented with heat.

\begin{tabular}{|c|c|c|c|c|c|c|}
\hline \multicolumn{2}{|c|}{ Behavioural stimuli } & \multirow[t]{2}{*}{$\mathbf{N}$} & \multirow[t]{2}{*}{$\mathbf{P}$} & \multirow[t]{2}{*}{ Person } & \multicolumn{2}{|c|}{ Mosquito behavioral responses } \\
\hline Person & Other & & & & $\mathrm{n}$ & Net attraction \\
\hline LA & $\begin{array}{l}\text { Standard Blend + } \\
\text { Heat }\end{array}$ & 8 & 0.001 & $73 \%$ & 553 & $0.18^{a}$ \\
\hline LA & Blend IB1 + Heat & 8 & 0.016 & $61 \%$ & 505 & $0.21^{a}$ \\
\hline LA & Worn sock + Heat & 8 & 0.650 & $52 \%$ & 579 & $0.13^{b}$ \\
\hline$H A$ & $\begin{array}{l}\text { Standard Blend + } \\
\text { Heat }\end{array}$ & 8 & 0.001 & $100 \%$ & 651 & $0.33^{c}$ \\
\hline $\mathrm{HA}$ & Blend IB1 + Heat & 8 & 0.001 & $99 \%$ & 568 & $0.31^{c}$ \\
\hline $\mathrm{HA}$ & Worn sock + Heat & 8 & 0.001 & $97 \%$ & 595 & $0.19^{a}$ \\
\hline
\end{tabular}

$\mathrm{N}$ refers to the number of replicates. $\mathrm{P}$ values $(\mathrm{P})$ indicate the level of statistical difference between pairs of contrasting stimuli i.e. person versus competing behavioural stimuli (other). Percentages of mosquitoes attracted to the persons are shown. The total number of mosquitoes collected in the choice and trap chambers ( $n$ ) and the proportion of these that were attracted to either behavioural stimulus (Net attraction) are shown. Values followed by different letter superscripts in the same column differ significantly.

heat $\left(24.98^{\circ} \mathrm{C}\right)$. However, person LA attracted a significantly higher proportion of mosquitoes when compared to the standard blend (73\% versus $27 \%, \mathrm{P}<0.001)$ and blend IB1 (61\% versus $39 \%, \mathrm{P}=0.016)$ when each was augmented with heat $\left(24.98^{\circ} \mathrm{C}\right)$ (Table 3$)$. Person LA attracted a significantly higher proportion of mosquitoes when compared to the standard blend (99\% versus $1 \%, \mathrm{P}$ $<0.001$ ), blend IB1 (98\% versus $2 \%, \mathrm{P}<0.001$ ) or his worn socks (98\% versus $2 \%, \mathrm{P}<0.001)$ when each was augmented with moisture (75.28\%) (Table 4). Although person LA attracted a significantly higher proportion of mosquitoes compared to the standard blend (100\% versus $0 \%, \mathrm{P}<0.001)$ and his worn socks $(80 \%$ versus $20 \%, \mathrm{P}<$ $0.001)$ when each was augmented with heat $\left(24.98^{\circ} \mathrm{C}\right)$ and moisture $(75.28 \%)$, there was no difference in the proportion of mosquitoes attracted to him when compared to blend IB1 (41\% versus 59\%, P = 0.416) augmented with heat $\left(24.98^{\circ} \mathrm{C}\right.$ ) and moisture (75.28\%) (Table 4).

Person HA attracted a significantly higher proportion of mosquitoes when compared to the standard blend 
Table 4 Attraction of Anopheles gambiae to humans versus odours of synthetic and natural origin augmented with moisture.

\begin{tabular}{|c|c|c|c|c|c|c|}
\hline \multicolumn{2}{|c|}{ Behavioural stimuli } & \multirow[t]{2}{*}{$\mathbf{N}$} & \multirow[t]{2}{*}{$\mathbf{P}$} & \multirow[t]{2}{*}{ Person } & \multicolumn{2}{|c|}{ Mosquito behavioral responses } \\
\hline Person & Other & & & & $n$ & Net attraction \\
\hline LA & $\begin{array}{l}\text { Standard Blend + } \\
\text { Moisture }\end{array}$ & 8 & 0.001 & $99 \%$ & 663 & $0.21^{\mathrm{ab}}$ \\
\hline LA & $\begin{array}{l}\text { Blend IB1 + } \\
\text { Moisture }\end{array}$ & 8 & 0.001 & $98 \%$ & 627 & $0.22^{\mathrm{a}}$ \\
\hline LA & $\begin{array}{l}\text { Worn sock + } \\
\text { Moisture }\end{array}$ & 8 & 0.001 & $98 \%$ & 589 & $0.18^{\mathrm{b}}$ \\
\hline $\mathrm{HA}$ & $\begin{array}{l}\text { Standard Blend + } \\
\text { Moisture }\end{array}$ & 8 & 0.001 & $100 \%$ & 611 & $0.28^{c}$ \\
\hline $\mathrm{HA}$ & $\begin{array}{l}\text { Blend IB1 + } \\
\text { Moisture }\end{array}$ & 8 & 0.001 & $100 \%$ & 643 & $0.24^{\mathrm{ac}}$ \\
\hline $\mathrm{HA}$ & $\begin{array}{c}\text { Worn sock + } \\
\text { Moisture }\end{array}$ & 8 & 0.001 & $99 \%$ & 551 & $0.28^{c}$ \\
\hline
\end{tabular}

$\mathrm{N}$ refers to the number of replicates. $\mathrm{P}$ values $(\mathrm{P})$ indicate the level of statistical difference between pairs of contrasting stimuli i.e. person versus competing behavioural stimuli (other). Percentages of mosquitoes attracted to the persons are shown. The total number of mosquitoes collected in the choice and trap chambers ( $n$ ) and the proportion of these that were attracted to either behavioural stimulus (Net attraction) are shown. Values followed by different letter superscripts in the same column differ significantly.

(100\% versus $0 \%, \mathrm{P}<0.001$ ), blend IB1 (99\% versus $1 \%$, $\mathrm{P}<0.001)$ or his worn socks (97\% versus $3 \%, \mathrm{P}<0.001$ ) when each was augmented with heat $\left(25.5^{\circ} \mathrm{C}\right)$ (Table 3$)$. He similarly attracted a significantly higher proportion of mosquitoes when compared to the standard blend (100\% versus $0 \%, \mathrm{P}<0.001)$, blend IB1 (100\% versus $0 \%, \mathrm{P}<0.001)$ or his worn socks $(99 \%$ versus $1 \%, \mathrm{P}<$ 0.001 ) when each was augmented with moisture (80.43\%) (Table 4). As well, person HA attracted a significantly higher proportion of mosquitoes when compared to the standard blend (98\% versus $2 \%, \mathrm{P}<0.001$ ), blend IB1 (99\% versus $1 \%, \mathrm{P}<0.001)$ or his worn socks (100\% versus $0 \%, \mathrm{P}<0.001)$ when each was augmented with heat $\left(25.5^{\circ} \mathrm{C}\right)$ and moisture $(80.43 \%)$ (Table 5$)$.

\section{Discussion}

This study demonstrates the importance of olfactory cues in mediating the host-seeking behaviour of Anopheles gambiae under semi-field conditions. Since evaluations were based on mosquito behavioural responses at short range [33,37], the results cannot be extrapolated to explain events that occur in the medium and longrange phases of attraction. The apparent lability between the behaviour of field and laboratory mosquito populations [38] also restricts interpretation of the results to the semi-field situations under which experiments were conducted. Inherent differences in human attractiveness to mosquitoes $[29,33,39,40]$ were seen to affect the efficacy of synthetic attractant blends in attracting the

Table 5 Attraction of Anopheles gambiae to humans versus odours of synthetic and natural origin augmented with heat plus moisture.

\begin{tabular}{|c|c|c|c|c|c|c|}
\hline \multicolumn{2}{|c|}{ Behavioural stimuli } & \multirow[t]{2}{*}{$\mathbf{N}$} & \multirow[t]{2}{*}{$\mathbf{P}$} & \multirow[t]{2}{*}{ Person } & \multicolumn{2}{|c|}{ Mosquito behavioral responses } \\
\hline Person & Other & & & & $\mathbf{n}$ & Net attraction \\
\hline LA & $\begin{array}{c}\text { Standard Blend + } \\
\text { Heat + Moisture }\end{array}$ & 8 & 0.001 & $100 \%$ & 539 & $0.19^{a}$ \\
\hline $\mathrm{LA}$ & $\begin{array}{c}\text { Blend IB1 + Heat + } \\
\text { Moisture }\end{array}$ & 8 & 0.416 & $41 \%$ & 634 & $0.04^{b}$ \\
\hline$L A$ & $\begin{array}{l}\text { Worn sock + Heat } \\
\quad+\text { Moisture }\end{array}$ & 8 & 0.001 & $80 \%$ & 614 & $0.11^{c}$ \\
\hline $\mathrm{HA}$ & $\begin{array}{l}\text { Standard Blend + } \\
\text { Heat + Moisture }\end{array}$ & 8 & 0.001 & $98 \%$ & 673 & $0.13^{c}$ \\
\hline $\mathrm{HA}$ & $\begin{array}{c}\text { Blend IB1 + Heat + } \\
\text { Moisture }\end{array}$ & 8 & 0.001 & $99 \%$ & 669 & $0.25^{d}$ \\
\hline $\mathrm{HA}$ & $\begin{array}{l}\text { Worn sock + Heat } \\
\quad+\text { Moisture }\end{array}$ & 8 & 0.001 & $100 \%$ & 631 & $0.08^{\mathrm{e}}$ \\
\hline
\end{tabular}

$\mathrm{N}$ refers to the number of replicates. $\mathrm{P}$ values $(\mathrm{P})$ indicate the level of statistical difference between pairs of contrasting stimuli i.e. person versus competing behavioural stimuli (other). Percentages of mosquitoes attracted to the persons are shown. The total number of mosquitoes collected in the choice and trap chambers $(n)$ and the proportion of these that were attracted to either behavioural stimulus (Net attraction) are shown. Values followed by different letter superscripts in the same column differ significantly. 
mosquitoes. This calls for caution whenever human subjects participate as volunteers in field efficacy, effectiveness and epidemiological studies.

The high proportion of mosquitoes caught in the trapping chambers in the absence of human cues i.e. by empty tents is hard to explain. Two hypotheses are construed. The first is that moving air is an activator for An. gambiae. The second is that An. gambiae, having evolved with humans and being highly anthropophilic [41], exhibits behavioural responses not only to humanderived chemical stimuli but also to behavioural stimuli originating from items commonly found in human dwellings and in the intra domiciliary environment. It is noteworthy that no mosquitoes were attracted to any of the tents when both were empty. This, coupled with the fact that there were no differences in the proportion of mosquitoes trapped when the two tents were baited with the same stimulus i.e. standard blend confirms that the behavioural responses were symmetrical. That differences in relative attractiveness between two persons could be discerned was not surprising. This is in conformity with previous studies where a similar discriminatory system was used [33,37,42].

Each of the two volunteers, one less and the other highly attractive to An. gambiae [33], attracted a higher proportion of mosquitoes when compared to empty tents or the standard blend. Anopheles gambiae prefers to feed on humans rather than other animal hosts $[1,2,43]$. Thus, it is not surprising that relatively more mosquitoes were attracted by the humans. This finding concurs with those reported by Mboera et al [44] and Mukabana et al [37], although evolutionary plasticity in the behaviour of field and laboratory populations exists [38]. The standard blend used in this study contained carbon dioxide (released at $500 \mathrm{ml} / \mathrm{min}$ ), ammonia (2.5\%) and distilled water. Failure of this blend to attract more or as many mosquitoes as a human may be attributed to (i) its limited chemical composition relative to the large diversity of compounds emanating from humans $[45,46]$, (ii) lack of constituents active in the short range phase of attraction as limited by the experimental setup [33], and (iii) lack of compounds distinctive and specific of human odour [47].

Whereas the proportion of mosquitoes attracted to the less attractive person versus Ifakara blend 1 (IB1) or his worn socks did not differ; far more mosquitoes were attracted to the highly attractive person relative to IB1 and his worn socks. Furthermore, the total proportion of mosquitoes attracted were low and high when the less and highly attractive persons were used as controls, respectively. This was irrespective of the contrasting behavioural stimuli against which they were compared and whether the stimuli were augmented with heat, moisture or both. These findings suggest that the inherent differences in peoples' attractiveness to hostseeking mosquitoes $[29,33,39,40]$ undermine the use of human subjects as screens for potential mosquito attractants [32]. It, therefore, matters the identity of the specific human subject against whom candidate mosquito attractants are screened. A standard, highly stringent positive control for screening candidate mosquito attractants should be sought. A good positive control, while closely depicting the key 'essence-of-man', should maintain a high and relatively unchanged degree of attraction to host-seeking mosquitoes under standardized climatic conditions.

Lack of statistical difference in the proportion of mosquitoes attracted to the less attractive person versus his worn socks indicates that the degree of attractiveness to mosquitoes is dictated by foot odours. This corroborates previous findings in which An. gambiae was shown to have a distinct preference for biting the legs and feet $[48,49]$. Several authors have since demonstrated attraction of An. gambiae to human foot odours [24,26,27]. However, because total body emanations of the highly attractive person attracted far more mosquitoes than his worn socks suggests that sources of attractive odours abound in other human body parts. Indeed, there are several reports of attraction of An. gambiae to material obtained from body parts other than the feet $[29,50,51]$.

The highly attractive individual attracted far more mosquitoes ( $\geq 97 \%$ ) than the standard blend, blend IB1 or his worn socks when these behavioural stimuli were augmented with heat, moisture or both. If both physical and chemical cues are responsible for attracting hostseeking mosquitoes to humans $[5,52,53]$ then it is plausible to infer that behavioural stimuli emanating from the highly attractive individual had combinations of both cues. The complimentary thinking is that the critical chemical compounds responsible for attracting hostseeking mosquitoes to humans were not present in the contrasting behavioural stimuli. This reasoning partially applies to data associated with the less attractive individual who was more attractive when the three behavioural stimuli were augmented with moisture alone or when the standard blend was augmented with heat, moisture or both.

Augmenting blend IB1 with heat or moisture did not increase its attractiveness over the less attractive individual, however, adding heat plus moisture rendered these contrasting sources of behavioural stimuli equally attractive to An. gambiae. This implies, in concurrence with published literature, that heat and moisture have a synergistic effect on the attraction of mosquitoes to odour baits $[6,54,55]$. Furthermore, the less attractive individual remained as attractive as his worn socks augmented with heat, but more attractive against his worn socks augmented either with moisture alone or with 
heat plus moisture. This finding underscores similarities in the behaviour of An. gambiae and other mosquito species. Even though heat may act synergistically with odour baits to increase their attraction to mosquitoes [28,55-58], this phenomenon is, with few exceptions [6], overridden in the presence of moisture, which reduces attraction of mosquitoes to odour baits [54]. Mosquitoes used in this study were starved for eight hours during which period they were supplied with water on cotton wicks. Water-satiated mosquitoes, unlike thirsty counterparts, are known to avoid environments with high relative humidity [54]. This potentially explains why the volunteers consistently attracted more mosquitoes over odour baits augmented with moisture. An exception to this was recorded when the less attractive person was compared to blend IB1 augmented with heat plus moisture.

Failure of heat and moisture to change the relative attractiveness of mosquitoes to the candidate odour baits can be attributed to temperature and relative humidity fluctuations i.e. between $25-27^{\circ} \mathrm{C}$ and $75-85 \%$, respectively. As small differences in the levels of these parameters can associate with major differences in mosquito behavioural responses [59], this may have been the case in our experiments. Anopheles gambiae, being highly anthropophlic $[1,2,43]$, has evolved to respond to human-specific rather than generalist cues. Ideally, heat and moisture, being host-unspecific, should, in interaction with other host-specific cues at short range [6,41], be indicative of the physical presence of hosts and thus important in inducing landing rather than act as cues mediating directional responses on their own. In our experimental setup attracted mosquitoes were trapped while flying upwind towards the odour baits, so excluding the behavioural end point of landing.

Of the three sources of behavioural stimuli tested, Blend IB1 emerged as the most potent mosquito attractant. The proportion of mosquitoes attracted to it equalled those attracted to the less attractive human subject when the blend was used on its own or when it was augmented with heat plus moisture. Except in one case [26], the key components of blend IB1 have been shown to be highly attractive to mosquitoes under laboratory $[12,13]$, semi-field $[15]$ and field conditions $[14,15]$. The fact that blend IB1 was consistently less attractive than the highly attractive human subject suggests that more compounds need to be added to blend IB1 and the concentrations of the existing ones refined.

\section{Conclusion}

This study, in concordance with existing literature $[5,8,52,53,60,61]$, supports previous reports that olfactory cues are the important signals mediating mosquito host location. Heat and moisture enhanced attraction of mosquitoes to candidate odour baits but did not influence the relative attractiveness of the odour baits. That results of attraction of the mosquitoes to the different odour blends varied depending upon the human subject against which they were screened implies that a standard, highly stringent positive control should be sought. Only then can we compare data across different ecological zones, mosquito populations, seasons and experimental setups (i.e. under laboratory, field and semi-field conditions) effectively.

\section{Acknowledgements}

We thank Mr. David Alila for rearing mosquitoes. The two male volunteers aged 32 and 33 years old are thanked for willingfully and dedicatedly participating in the study. Mr. Fredros Oketch Okumu and Dr. Sarah Moore are thanked for participating in the initial discussions about the experimental ideas. They also formulated the attractant blends including mechanisms for their delivery. This study was funded by a grant from the Foundation for the National Institutes of Health (FNIH) through the Grand Challenges in Global Health initiative (GCGH \#121).

\section{Author details}

${ }^{1}$ International Centre of Insect Physiology and Ecology, PO Box 30772 00100, GPO, Nairobi, Kenya. ${ }^{2}$ Department of Zoological Sciences, Kenyatta University, PO Box 43844 - 00100 GPO, Nairobi, Kenya. ${ }^{3}$ School of Biological Sciences, University of Nairobi, PO Box 30197 - 00100 GPO, Nairobi, Kenya.

\section{Authors' contributions}

WRM conceived of the study and designed experiments. WRM designed the experimental setup. EAO carried out experiments with the assistance of MNO. Data analysis was done by EAO together with MNO and WRM. WRM interpreted the data assisted by EAO, MNO, PAM and EDK. WRM wrote the manuscript assisted by EAO. All authors revised the manuscript.

\section{Competing interests}

The authors declare that they have no competing interests.

Received: 6 August 2009

Accepted: 6 January 2010 Published: 6 January 2010

\section{References}

1. White GB: Anopheles gambiae complex and disease transmission in Africa. Trans R Soc Trop Med Hyg 1974, 68:278-301.

2. Gillies MT, Coetzee M: A supplement to the Anophelinae of Africa South of the Sahara Publication no. 55. The South African Institute for Medical Research, Johannesburg, South Africa 1987.

3. Coetzee M, Craig M, Le Sueur D: Distribution of African malaria mosquitoes belonging to the Anopheles gambiae complex. Parasitol Today 2000, 16:74-77.

4. Coetzee M: Distribution of the African malaria vectors of the Anopheles gambiae complex. Am J Trop Med Hyg 2004, 70:103-104.

5. Takken W, Knols BGJ: Odor-mediated behavior of Afrotropical malaria mosquitoes. Annu Rev Entomol 1999, 44:131-57.

6. Takken W, Knols BGJ, Otten H: Interactions between physical and olfactory cues in the host-seeking behaviour of mosquitoes: the role of relative humidity. Ann Trop Med Parasitol 1997, 91:119-120.

7. Costantini C, Gibson G, Brady J, Merzagora L, Coluzzi M: A new odourbaited trap to collect host-seeking mosquitoes. Parassitologia 1993, 35:5-

8. Logan JG, Birkett MA: Semiochemicals for biting fly control: their identification and exploitation. Pest Manag Sci 2007, 63:647-657.

9. Logan JG, Birkett MA, Clark SJ, Powers S, Seal NJ, Wadhams LJ, Mordue AJ, Pickett JA: Identification of human-derived volatile chemicals that interfere with attraction of Aedes aegypti mosquitoes. J Chem Ecol 2008, 34:308-322.

10. Acree F, Turner RB, Gouck HK, Beroza M, Smith N: L-Lactic acid: a mosquito attractant isolated from humans. Science 1968, 161:1346-1347. 
11. Smith CN, Smith N, Gouck HK, Weidhaas DE, Gilbert $H$, Mayer MS, Smittle BJ, Hofbauer A: L-Lactic acid as a factor in the attraction of Aedes aegypti (Diptera: Culicidae) to human hosts. Ann Entomol Soc Am 1970, 63:760-770.

12. Knols BGJ, Loon JJA, Cork A, Robinson DR, Adam W, Meijerink J, De Jong R, Takken W: Behavioural and electrophysiological responses of the female malaria mosquito Anopheles gambiae (Diptera: Culicidae) to Limburger cheese volatiles. Bull Entomol Res 1997, 87:151-159.

13. Smallegange RC, Qiu YT, van Loon JJ, Takken W: Synergism between ammonia, lactic acid and carboxylic acids as kairomones in the hostseeking behaviour of the malaria mosquito Anopheles gambiae sensu stricto (Diptera: Culicidae). Chem Senses 2005, 30:145-152.

14. Qiu YT, Smallegange RC, Ter BC, Spitzen J, Van Loon JJ, Jawara M, Milligan P, Galimard AM, Van Beek TA, Knols BG, Takken W: Attractiveness of MM-X traps baited with human or synthetic odor to mosquitoes (Diptera: Culicidae) in The Gambia. J Med Entomol 2007, 44:970-983.

15. Okumu FO, Killeen GF, Biswaro L, Smallegange RC, Mbeleyela E, Titus E, Munk C, Ngonyani H, Takken W, Mshinda H, Mukabana R, Moore SJ: Trapping malaria vectors using synthetic odors that are more attractive than humans. PLOS ONE

16. Kline DL: Semiochemicals, traps/targets and mass trapping technology for mosquito management. J Am Mosq Control Assoc 2007, 23(2 Suppl):241-251.

17. Kline $D L$, Lemire GF: Evaluation of attractant baited traps/targets for mosquito management on Key Island, Florida, USA. J Vect Ecol 1998, 23:171-185.

18. Stivers J: Research - completed projects. Stevens' Landing http://www. collier-mosquito.org/stevens_landing.php, (accessed November 30, 2009)..

19. Day JF, Sjogren RD: Vector control by removal trapping. Am J Trop Med Hyg 1994, 50:126-133.

20. Healy TP, Copland MJ: Human sweat and 2-oxopentanoic acid elicit a landing response from Anopheles gambiae. Med Vet Entomol 2000, 14:195200.

21. Healy TP, Copland MJ, Cork A, Przyborowska A, Halket JM: Landing responses of Anopheles gambiae elicited by oxocarboxylic acids. Med Vet Entomol 2002, 16:126-132.

22. Kline L: Traps and trapping techniques for adult mosquito control. J Am Mosa Control Assoc 2006, 22:490-496.

23. Kröckel U, Rose A, Eiras A, Geier M: New tools for surveillance of adult Aedes aegypti: comparison of trap catches with human landing collections in an urban environment. J Am Mosa Control Assoc 2006, 22:229-238.

24. Njiru BN, Mukabana WR, Takken W, Knols BGJ: Trapping of the malaria vector Anopheles gambiae with odour-baited MM-X traps in semi-field conditions in western Kenya. Malar J 2006, 5:39.

25. Roelefs WL, ed: Establishing efficacy of sex attractants and disruptants for insect control. Entomological Society of America Bull 1979, 97:147.

26. Murphy MW, Dunton RF, Perich MJ, Rowley WA: Attraction of Anopheles (Diptera: Culicidae) to volatile chemicals in Western Kenya. J Med Entomol 2001, 38:242-244.

27. Schmied WH, Takken W, Killeen GF, Knols BG, Smallegange RC: Evaluation of two counterflow traps for testing behaviour-mediating compounds for the malaria vector Anopheles gambiae s.s. under semi-field conditions in Tanzania. Malar J 2008, 7:230.

28. Eiras $A E$, Jepson PC: Responses of female Aedes aegypti (Diptera: Culicidae) to host odours and convection currents using an olfactometer assay. Bull Entomol Res 1994, 84:207-211.

29. Qiu YT, Smallegange RC, Van Loon JJ, Ter Braak CJ, Takken W: Interindividual variation in the attractiveness of human odours to the malaria mosquito Anopheles gambiae s. s. Med Vet Entomol 2006, 20:280 287.

30. Williams CR, Bergbauer R, Geier M, Kline DL, Bernier UR, Russell RC, Ritchie SA: Laboratory and field assessment of some kairomone blends for host-seeking Aedes aegypti. J Am Mosq Control Assoc 2006, 22:641-647.

31. Torr S, Della Torre A, Calzetta M, Costantini C, Vale GA: Towards a fuller understanding of mosquito behaviour: use of electrocuting grids to compare the odour-orientated responses of Anopheles arabiensis and An. quadriannulatus in the field. Med Vet Entomol 2008, 22:93-108.

32. Brady J, Costantini C, Sagnon N, Gibson G, Coluzzi M: The role of body odours in the relative attractiveness of different men to malarial vectors in Burkina Faso. Ann Trop Med Parasitol 1997, 91(Suppl. 1):S121-S122.
33. Mukabana WR, Takken W, Coe R, Knols BGJ: Host-specific cues cause differential attractiveness of Kenyan men to the malaria mosquito Anopheles gambiae. Malar J 2002, 1:17.

34. Grafen A, Rosie H: Modern statistics for the life sciences. Categorical data Oxford University Press, Oxford 2005.

35. Agresti A: Categorical data analysis New York, Wiley 1990.

36. Payne CD, ed: The GLIM manual, Release 3.77. Numerical algorithms Group, Oxford 1986

37. Mukabana WR, Takken W, Killeen GF, Knols BGJ: Allomonal effect of breath contributes to differential attractiveness of humans to the African malaria vector Anopheles gambiae. Malar J 2004, 3:1.

38. Lefèvre T, Gouagna L, Dabire KR, Elguero E, Fontenille D, Costantini C, Thomas C: Evolutionary lability of odour-mediated host preference by the malaria vector Anopheles gambiae. Trop Med Int Health 2009, 14:228236.

39. Lindsay SW, Adiamah JH, Miller JE, Pleass RJ, Armstrong JRM: Variation in attractiveness of human subjects malaria mosquitoes (Diptera: Culicidae) in The Gambia. J Med Entomol 1993, 30:368-373.

40. Knols BGJ, De Jong R, Takken W: Differential attractiveness of isolated humans to mosquitoes in Tanzania. Trans R Soc Trop Med Hyg 1995, 89:604-606

41. Costantini C, Sagnon NF, Torre AD, Coluzzi M: Mosquito behavioural aspects of vector-human interactions in the Anopheles gambiae complex. Parassitologia 1999, 41:209-217.

42. Lacroix R, Mukabana WR, Gouagna LC, Koella JC: Malaria infection increases attractiveness of humans to mosquitoes. PLOS Biol 2005, 3:e298.

43. Pates HV, Takken W, Stuke K, Curtis CF: Differential behaviour of Anopheles gambiae sensu stricto (Diptera: Culicidae) to human and cow odours in the laboratory. Bull Entomol Res 2001, 91:289-296.

44. Mboera LEG, Knols BGJ, Della Torre A, Takken W: The response of Anopheles gambiae s.l. and Anopheles funestus (Diptera: Culicidae) to tents baited with human odour or carbon dioxide in Tanzania. Bull Entomol Res 1997, 87:173-178.

45. Krotozynski B, Gabriel G, O'Neill H: Characterization of human expired air: A promising investigative and diagnostic technique. J Chromatogr Sci 1977, 15:239-244.

46. Bernier UR, Kline DL, Barnard DR, Schreck CE, Yost RA: Analysis of human skin emanations by gas chromatography/mass spectrometry. 2 . Identification of volatile compounds that are candidate attractants for the yellow fever mosquito (Aedes aegypti). Anal Chem 2000, 72:747-756.

47. Stoddart DM: The Scented Ape (The biology and culture of human odour) Cambridge: Cambridge University Press 1990.

48. De Jong R, Knols BGJ: Selection of biting sites on man by two malaria mosquito species. Experientia 1995, 51:80-84.

49. Dekker T, Takken W, Knols BGJ, Bouman E, Laak SVD, Bever AD, Huisman PWT: Selection of biting sites on a human host by Anopheles gambiae s. s, An arabiensis and An. quadriannulatus. Entomol Exp Appl 1998, 87:295-300.

50. Braks MAH, Cork A, Takken W: Olfactometer studies on the attraction of Anopheles gambiae sensu stricto (Diptera: Culicidae) to human sweat. Proc Exp Appl Entomol 1997, 8:99-104.

51. Braks MAH, Takken W: Incubated human sweat but not fresh sweat attracts the malaria mosquito Anopheles gambiae sensu stricto. J Chem Ecol 1999, 25:663-672.

52. Sutcliffe JF: Distance orientation of biting flies to their hosts. Insect Sci Appl 1987, 8:611-616.

53. Takken W: The role of olfaction in host-seeking of mosquitoes: a review Insect Sci Appl 1991, 12:287-291.

54. Bar-Zeev M, Maibach HI, Khan AA: Studies on the attraction of Aedes aegypti (Diptera: Culicidae) to man. J Med Entomol 1977, 14:113-120.

55. Kline DL, Lemire GF: Field evaluation of heat as an added attractant to traps baited with carbon dioxide and octenol for Aedes taeniorhynchus. $J$ Am Mosa Control Assoc 1995, 11:454-456.

56. Clements AN: The biology of mosquitoes. Sensory reception and behaviour Chapman and Hall, London 1999, 2.

57. Khan AA, Maibach HI: Quantitarion of effect of several stimuli on landing and probing by Aedes aegypti. J Econ Entomol 1966, 59:902-905.

58. Khan AA, Maibach HI, Strauss WG, Fenley WR: Quantitation of effect of several stimuli on the approach of Aedes aegypti. J Econ Entomol 1966, 59:690-694. 
59. Smart MR, Brown AWA: Studies on the responses of the female Aedes mosquito. Part VII: The effect of skin temperature, hue and moisture on the attractiveness of the human hand. Bull Entomol Res 1955, 47:89-100.

60. Dodd CS, Burgess NRH: Why do insects bite? A review of blood sucking behaviour. J R Army Med Corp 1995, 141:151-156.

61. Zweibel $\amalg$, Takken $W$ : Olfactory regulation of mosquito-host interactions. Insect Biochem Mol Biol 2004, 34:645-652.

doi:10.1186/1475-2875-9-6

Cite this article as: Olanga et al: Attraction of Anopheles gambiae to odour baits augmented with heat and moisture. Malaria Journal 2010 9:6.

Publish with Biomed Central and every scientist can read your work free of charge

"BioMed Central will be the most significant development for disseminating the results of biomedical research in our lifetime. " Sir Paul Nurse, Cancer Research UK

Your research papers will be:

- available free of charge to the entire biomedical community

- peer reviewed and published immediately upon acceptance

- cited in PubMed and archived on PubMed Central

- yours - you keep the copyright 